\title{
FENOMENA FIDGET SPINNER \\ Ditinjau Dari Sudut Pandang Konsumerisme dan Kultivasi Media Dengan Pendekatan Analisis Konten
}

\author{
${ }^{1}$ Alfirahmi \\ ${ }^{2}$ Hafizh Faikar A. R. \\ 1 \& 2 Institut Ilmu Sosial dan Manajemen STIAMI \\ 2 Program Studi Magister Ilmu Komunikasi, Universitas Indonesia \\ Email: ${ }^{1}$ alfirahmi.idrus@gmail.com, ${ }^{2}$ insanetheory1212@gmail.com
}

\section{ARTICLE INFO ABSTRACT}

Keywords:

Fidget spinner, consumptive culture, media cultivation.
The development of technology and information ultimately makes the flow of information exist in the absence of space and time or it is known as globalization. Information flow is spread easily and everyone can access any information without limitations. That phenomenon ultimately creates new models, trends, or new products to meet the growing needs of society. Trends or models that are developed in society through social media make consumers view advertisement easily as well as make them consumptive. One example of a consumptive culture is the presence of a spinner fidget toy. Fidget has been developing and getting great attention through the growing number of enthusiasts, and it is considered as a solution that can answer the needs of autism consumers. In addition, the development of spinner fidget toys is supported by the pattern of dissemination through social media that indirectly raises the buyer's interest in spinner fidget. Spinner fidget toy is only one of the few cases on how the purchasing power of society is limited to pleasure, and overriding the useful value of purchased goods. The unconscious community has the potential to become consumptive, and it affects mental development of the consumer level, and reduces the productivity of society. The purpose of this study is to analyze how the phenomenon of fidget spinner is viewed from the point of consumerism view and media cultivation with content analysis approach.

\section{Pendahuluan}

Teknologi yang berkembang pesat dan kuatnya arus informasi, menjadikan secara garis besar semua yang ada di dunia terhubung tanpa pemisah ruang dan waktu, atau biasa dikatakan dengan globalisasi. Globalisasi yang tidak memiliki ruang dan waktu, menuntut orang-orang yang tidak ikut dalam proses globalisasi tertinggal dan kehilangan jati diri. Budaya konsumerisme adalah salah satu dampak yang timbul akibat adanya globalisasi.

Lockwood (2003:2) mengatakan bahwa perluasan nilai materialisme dan kebebasan individu seiring dengan perubahan globalisasi ekonomi, pada akhirnya berdampak kepada nilai-nilai konsumsi serta konsumerisme. Sebagai contoh, masyarakat yang tadinya mempergunakan televisi sebagai media hiburan, berubah ketika masuknya era multimedia. Fungsi multimedia seperti youtube, streaming, pada akhirnya menghilangkan fungsi televisi, karena perkembangan multimedia jauh lebih pesat, seperti ketiadaan batasan dalam mengakses informasi.

Ketiadaan batasan ruang dan waktu dalam mengakses informasi berdampak kepada manusia, dimana ketika manusia masih berada dalam jalur lambat, tanpa mau mengikuti perkembangan teknologi dan informasi, ditinggalkan dan dianggap manusia aneh. Manusia yang tadinya masih berada pada taraf pemakai biasa, menjadi manusia dengan tingkat konsumerisme ${ }^{1}$ yang semakin menuntut perubahan. Fenomena inilah kemudian yang menciptakan ladang bisnis baru, di mana

\footnotetext{
${ }^{1}$ Indonesia jika melihat kepada survey yang dilakukan LIPI, menduduki kursi ketiga dengan tingkat konsumerisma paling besar melalui perbandingan dengan 106. Penjelasan dikutip dalam tribunnews.com tanggal 23 bulan Oktober 2017.
} 
tingkat kebutuhan masyarakat akan perubahan teknologi dan informasi, menjadi aset yang diperjual belikan. Produsen berlomba menarik perhatian masyarakat terhadap produk yang dihasilkan, mengesampingkan fungsi dari produk yang diperjualbelikan, dan menjadikan keuntungan sebagai pilihan pertama dalam berbisnis.

Melihat ke masa lalu, tepatnya pada pertengahan tahun 1960an dengan diperkenalkannya televisi, bisa dikatakan masyarakat yang ditemui pada masa itu adalah mereka yang masih hidup dengan tingkat konsumerisme rendah. Hal ini tentu tidak terlepas dari tingkat perekonomian masyarakat yang masih rendah. Namun, masyarakat pada masa tersebut adalah orang - orang yang "mudah bahagia". Hanya dengan televisi mereka mampu bahagia, berkumpul dengan seluruh anggota keluarga. Hal yang sama terlihat ketika seseorang hanya mampu membeli mobil, fungsi dari mobil adalah pertimbangan seseorang membeli dan mengesampingkan brand.

Seiring dengan perkembangan teknologi dan informasi melalui media baru (internet), tingkat konsumerisme masyarakat semakin meningkat. Indonesia sebagai salah satu Negara berkembang membutuhkan tujuh dekade untuk menuju ke perubahan budaya konsumtif walaupun memang perubahan budaya konsumtif tersebut telah dirasakan dari semenjak tahun 1960an ${ }^{2}$. Namun jika dibandingkan dengan budaya konsumtif Jepang yang mengalami peningkatan $80 \%$ tingkat konsumerisme dalam hitungan satu decade ${ }^{3}$, dimana budaya konsumtif di Jepang adalah barangbarang dengan brand besar, maka perubahan budaya konsumtif di Indonesia masih rendah. Perubahan budaya konsumtif yang besar di Indonesia adalah pada awal abad 20an, dimana masyarakat mulai memperhatikan brand seperti apple, Samsung, Gucci, dan Mercedes dalam setiap penampilan. Panjangnya antrian di depan app-store setiap kali rilis produk baru, hingga yang belum lama ini terjadi, yakni baku hantam antar pengunjung lantaran ada sebuah departemen store membuka diskon besar-besaran yang hanya berlangsung selama sehari, menjadi contoh perubahan budaya konsumtif di Indonesia.

Melihat perkembangan budaya konsumtif masyarakat, dapat dikatakan pada era modern, bentuk konsumtifitas manusia terhadap suatu barang tidak lagi terletak pada kebutuhannya (needs), melainkan pada hasrat (desire). Yasraf mengemukakan, satu-satunya objek yang dapat memenuhi hasrat adalah objek hasrat yang muncul dalam bawah sadar secara imajiner. Objek hasrat ini tidak menghilang dan hanya mampu mencari substitusi-substitusinya dalam dunia objek dari simbol-simbol yang dikonsumsi (Tamasya Melampaui Batas-Batas Kebudayaan, 2004).

Perkembangan teknologi dan informasi sebagai pendorong perubahan budaya konsumerisme di masyarakat terlihat dari banyaknya teknologi yang memberikan kemudahan dalam proses jual beli dengan metode online, dan kemudahan melakukan transaksi. Pada akhirnya pemahaman konsumerisme mulai bergeser sebagai respon terhadap pengulangan dari hal-hal lama, ke pencarian seperti produk baru, pengalaman baru dan citra baru, seperti media sosial.

Perkembangan media sosial menjadi cambuk bagi perubahan budaya konsumerisme, dimana budaya yang tampak adalah budaya "latah" karena trend, memenuhi tingkat sosial, dan pencitraan diri. Hal ini sejalan dengan Schor $^{4}$ yang menggambarkan situasi budaya konsumtif sebagai The New Consumerism, yaitu upaya peningkatan gaya hidup, keinginan untuk tampil diakui, prestise terhadap sebuah barang dan perlombaan untuk memilikinya, serta keterputusan antara keinginan konsumen dengan pendapatan. Pada akhirnya konsumerisme menjadi sebuah wabah, semakin lama menjamur dan menyebabkan ketergantungan. Masyarakat menjadi bekerja keras hanya demi memenuhi hasrat budaya konsumerisme yang selalu mengeluarkan trend terbaru ${ }^{5}$.

\footnotetext{
2 Sejalan dengan pernyataan Wick (1985), bahwa "Between 1960 and 1976 real expenditure per capita increased twice as rapidly in urban (40 percent) as in rural (20 percent) Java and faster in Jakarta (50 percent) than in any other city. Moreover, the increase of 40 percent in urban per capita expenditure was biased heavily toward the upper expenditure quintiles".

3 Dalam Mariska Liska, Konsumerisme sebagai faktor penarik terjadinya fenomena Enjokousai dalam masyarakat Jepang Kontemporer, penelitian yang dilakukan pada tahun 2011. Akses pada lib.ui.ac.id, tanggal 19 Maret 2018. Mariska menjelaskan bahwa perubahan budaya konsumerisme pada masyarakat Jepang terjadi dari tahun 1965-1977 dengan tingkat perubahan mencapai 80\%, dan perubahan budaya konsumerisme ini terjadi dalam semua lini masyarakat di Jepang, termasuk didalamnya adalah golongan petani, buruh.

4 Schor, Juliet. “The New Politics of Consumption”. In Dines \& Huez, pp.183-195.

5 Mariska Liska menjelaskan bahwa masyarakat Jepang semakin banyak mengkonsumsi barang-barang kebutuhan sekunder dan tersier. Tingkat konsumerisme masyarakat Jepang pada tahun 1970an, adalah
} 
Keberadaan media massa baru (internet), menjadi pintu bagi produsen memperluas jaringan penjualannya. Yang pasti, dengan keadaan seperti ini, sulit rasanya untuk memutus atau menghapuskan konsumerisme pada individu, apalagi bagi individu yang merasa semua berjalan secara begitu alami hingga konsumerisme ini tidak dianggap sebagai sesuatu yang menekan atau bernilai buruk.

Tren konsumerisme sendiri terjadi pada segala bidang, dan yang paling mudah untuk diamati adalah mainan. Di tahun 2003 misalnya, dilandasi film anime berjudul "Lets and Go", kepopuleran mainan Tamiya melejit dengan dahsyat. Karena kepopulerannya, berbagai instansi (bahkan yang sebenarnya tidak ada kaitannya sama sekali dengan mainan) marak mengadakan perlombaan Tamiya. Hadiahnya pun tidak main - main, sebuah mall besar sekelas matahari bahkan menawarkan hadiah hingga Rp. 15 Juta untuk juara pertama perlombaan mainan tamiya. Tak heran, mainan yang awalnya hanya dikonsumsi oleh anak - anak ini akhirnya berhasil menarik perhatian orang dewasa, entah dengan tujuan memenangkan perlombaan atau hanya sekedar hobi karena pada dasarnya memodifikasi Tamiya ini juga punya nilai kesenangan tersendiri.

Ketika kepopuleran Tamiya sudah mulai meredup, munculah mainan baru yang juga viral (walau tidak sepopuler Tamiya), mainan tersebut adalah Beyblade. Tidak jauh berbeda dengan Tamiya, kepopuleran beyblade diawali dengan ditayangkannya anime dengan judul yang sama dengan mainan ini. Pada dasarnya sistem permainan beyblade tidak jauh berbeda dengan gasing yang selama ini dikenal, hanya dikemas dalam bentuk yang sedikit lebih modern. Dalam viralnya permainan ini pun banyak instansi yang melakukan hal sama, mengadakan kompetisi.

Pada tahun 2017, kehadiran mainan fidget spinner, menjadi sebuah wahana baru bagi tingkat kebutuhan masyarakat akan hiburan. Fidget spinner misalnya, merupakan sebuah mainan kecil yang berputar diantara dua jari, dengan bentuk seperti baling-baling dengan bantalan peluru di tengahnya. Catherine Hettinger sebagai penemu fidget spinner, beranggapan bahwa dengan fidget spinner mampu mengalihkan perhatian anak-anak muda dan memberi mereka sesuatu yang menenangkan untuk melepaskan energi yang terpendam. Fidget spinner dianggap sebagai mainan yang diciptakan untuk memberi ketenangan dan dampak positif terhadap anak-anak berkebutuhan khusus (autis). Uniknya, kebanyakan konsumen fidget sppiner justru bukan dari kalangan anak autis, melainkan anak - anak yang sebenarnya tidak memiliki kebutuhan apa pun pada mainan ini.

Masyarakat pengguna fidget spinner datang dari usia muda sampai dengan dewasa, dan untuk harga per satuan tidaklah murah. Fenomena fidget spinner semakin kuat seiring dengan kemunculannya di media social, dan review atas mainan fidget spinner yang menciptakan wabah fidget spinner. Berbagai perusahaan kemudian mulai memproduksi fidget spinner, dan melakukan proses penjualan melalui iklan dengan tag-line "relaxing your stress".

Mainan seperti fidget spinner, adalah beberapa mainan yang datang dan berkembang akibat adanya budaya konsumerisme masyarakat yang berlebihan. Selain itu, kemajuan teknologi dan informasi mempunyai peran dalam menentukan dan mempercepat budaya konsumtif masyarakat. Logika yang bermain dimedia adalah percepatan aliran informasi yang baru, sehingga mainan seperti fidget spinner yang tadinya hanya merupakan mainan biasa tidak dikenal, dengan informasi di media mampu mendistorsi masyarakat untuk membeli mainan tersebut disamping nilai guna hanya sebagai hiburan.

Berdasarkan penjelasan di atas, penelitian ini bertujuan untuk melihat "Bagaimana Fenomena Fidget Spinner Ditinjau Dari Sudut Pandang Konsumerisme dan Kultivasi Media Dengan Pendekatan Analisis Konten".

\section{TINJAUAN TEORETIS}

\subsection{Teori Kultivasi}

Gagasan tentang cultivation theory (teori kultivasi) untuk pertama kalinya dikemukakan oleh George Gerbner bersama dengan rekan-rekannya di Annenberg School of Communication di Pannsylvania, tahun 1969, dalam sebuah artikel berjudul "the television World of Violence". Artikel tersebut merupakan salah satu tulisan dalam buku bertajuk Mass Media and Violence yang disunting D. Lange, R. Baker \& S. Ball (eds). Menurut Wood (2000) kata 'cultivation' sendiri merujuk pada

84\% masyarakat memiliki televisi, pendingin ruangan, dan 30\% memiliki mobil pribadi dengan angka konsumsi paling tinggi sebesar $80 \%$, dan hal ini terjadi akibat masuknya budaya barat ke Jepang. 
proses kumulatif di mana televisi menanamkan suatu keyakinan tentang realitas sosial kepada khalayaknya.

Selanjutnya Gerbner mengemukakan dua alasan yang menyebabkan terjadinya kultivasi, yaitu mainstreaming dan resonansi. Mainstreaming merupakan proses dimana ketika ide, simbol, dan informasi yang ditayangkan di TV mendominasi dan kemudian menghilangkan symbol, ide, dan informasi yang didapat dari media lain (Morissan, 2015; 523). Namun, seiring dengan perkembangan media sosial seperti youtube, streaming $T V$, bahwa media baru (internet) adalah sumber yang mampu mengalihkan atau menghilangkan symbol, ide, dan informasi sehingga orang berfokus kepada sumber dari media baru (internet).

Teori kultivasi pada dasarnya menyatakan bahwa media bertangggung jawab dalam membentuk atau mengkultivasi cara pandang pemirsa media terhadap realitas sosial. Efek massif televisi yang menerpa khalayak secara terus menerus secara bertahap membentuk persepsi tentang realitas sosial bagi individu dan budaya secara keseluruhan.

Gerbner berpendapat bahwa media massa menanamkan sikap-sikap serta nilai-nilai yang telah tersaji dalam suatu budaya melalui komunikasi satu arah bukan komunikasi dua arah. Media mengelola dan mempropaganda nilai-nilai tersebut diantara anggota sebuah budaya, kemudian mengikatnya bersama-sama. Media massa memiliki karakteristik media penyiaran yang khusus serta memudahkan dalam menanamkan berbagai sikap dan nilai budaya melalui audiovisual.

\subsection{Konsep Konsumerisme}

Sebelum kita membahas lebih jauh tentang konsumerisme, kita perlu tahu tentang makna dari konsumsi itu sendiri. Konsumsi, menurut Yasraf, dapat dimaknai sebagai sebuah proses objektifikasi, yaitu proses eksternalisasi atau internalisasi diri lewat objek-objek sebagai medianya (Yasraf, 2004). Maksudnya, bagaimana kita memahami dan mengkonseptualisasikan diri maupun realitas di sekitar kita melalui objek-objek material. Di sini terjadi proses menciptakan nilai-nilai melalui objek-objek dan kemudian memberikan pengakuan serta penginternalisasian nilai-nilai tersebut. Sebagai contoh, ketika kita membeli tas atau baju, kita akan memilih warnanya, modelnya, merk-nya, dan lain sebagainya, bukan hanya sekedar tas atau baju berdasarkan fungsinya sebagai barang tersebut. Warna, model, dan merk semuanya memiliki nilai yang kita inginkan untuk merealisasikan diri kita. Bagaimana dengan baju atau tas tersebut kita ingin dipandang sebagai orang yang tegas, orang yang berwibawa, atau apa pun.

Selanjutnya tentang konsumerisme. menurut Stearns (2003):

.. consumerism is best defined by seeing how it emerged.but obviously we need some preliminary sense of what we are talking about. Consumerism describes a society in which many people formulate their goals in life partly through acquiring goods that they clearly do not need for subsistence or for traditional display. They become enmeshed in the process of acquisition shopping and take some of their identity from a possession of new things that they buy and exhibit. In this society, a host of institutions both encourage and serve consumerism.. from eager shopkeepers trying to lure customers into buying more than they need to produce designer employed toput new twists on established models, to advertisers seeking ti create new needs."

Konsumerisme dapat diartikan sebagai sebuah ideologi yang beranggapan bahwa kehidupan dapat dinilai atau dimaknai berdasarkan material atau barang yang dikonsumsi. Ilmuan lain, Baudrillard (2004), melalui pandangan semiotikanya memberikan analisis yang original tentang masyarakat konsumen, dan juga dapat menjelaskan bagaimana struktur komunikasi dan sistem tanda mampu mempertahankan eksistensi masyarakat konsumen tersebut. Analisa Baudrillard tentang masyarakat konsumsi disarikan melalui analisa dari disiplin semiotika, psikoanalisa dan ekonomi politik dalam produksi tanda. Menurut Baudrillard, sistem komunikasi berperan sangat penting dalam masyarakat konsumen, terutama menyangkut produksi tanda.

Dalam masyarakat konsumen, nilai guna atau use value dari suatu barang menjadi kabur. Mereka tidak lagi membeli barang brdasarkan kebutuhan (needs), namun lebih sebagai pemenuhan hasrat (desire). Yasraf, Gilles Deleuze dan Felix Guattari (2004) menyatakan bahwa hasrat atau hawa nafsu tidak pernah terpenuhi, karena ia selalu direproduksi dalam bentuk yang lebih tinggi. Orang mempunyai hasrat akan sebuah objek tidak disebabkan kebutuhan alamiah pada objek tersebut, akan tetapi perasaan kekurangan dan ketidakpuasan yang diproduksi dan direproduksi dalam diri masing- 
masing. Dengan kata lain, yang sebenarnya dibeli atau dikonsumsi oleh masyarakat pasca modern bukan lagi objeknya, sebagaimana yang dikatakan Baudrillard, yang dikonsumsi bukan lagi use atau exchange value, melainkan "symbolic value", maksudnya orang tidak lagi mengkonsumsi objek berdasarkan karena kegunaan atau nilai tukarnya, melainkan karena nilai simbolis yang sifatnya abstrak dan terkonstruksi.

\subsection{Konsep Marketing 3.0}

Pemasaran pada era digital informasi seperti saat ini berjalan begitu cepat, dimulai Marketing 1.0, Marketing 2.0, dan Marketing 3.0. Marketing 3.0: From Products to Customers to Human Spirit diperkenalkan oleh Philip Kotler, Hermawan Kartajaya dan Iwan Setiawan Marketing 3.0 merupakan respon dari perkembangan komponen pemasaran itu sendiri yang berangkat dari komponen klasik yaitu 4 P; Product, Price, Place, Promotion hingga menjadi 4Cs yang dua arah hingga multi arah

Marketing 1.0 adalah marketing yang berfokus pada produk atau dengan istilah lain disebut "Product-Centric Era". Dimana kegiatan marketing diarahkan sesuai dengan kemauan produsen. Disini, konsumen sedikit diabaikan dan yang penting adalah bagaimana produsen membuat produk yang bagus dan laku dipasaran. Marketing 2.0 adalah marketing yang berfokus pada pelanggan, dengan istilah lain disebut "Customer-Centric Era". Lebih maju dari Marketing 1.0, disini kegiatan marketing diarahkan sesuai dengan kemauan pelanggan. Selain produk yang bagus juga memperhatikan aspek keinginan pasar yang ada.

Konsep yang paling mutakhir adalah Marketing 3.0, yaitu marketing yang berfokus pada kemanusiaan, dan disebut dengan "Human-Centric Era". Kegiatan marketing produk bukan yang utama lagi, karena disini pelaku bisnis justru lebih menonjol aktifitas kemanusiaannya, dengan berbagai kegiatan sosial maupun pelestarian lingkungan hidup. Konsumen dipandang sebagai manusia seutuhnya, bukan lagi sekadar manusia yang memiliki kebutuhan dasar secara fisik. Aspek spiritual konsumen inilah yang menjadikan marketing 3.0 berbeda dengan marketing sebelumnya. Pada era marketing 3.0, posisi produsen dan konsumen menjadi bias, sehingga istilah prosumer (producer is also consumer) menjadi populer karena saat ini setiap orang bisa menjadi produsen sekaligus konsumen sehingga tidak jelas lagi siapa menjual kepada siapa, atau lebih dikenal dengan istilah Crowd Combo.

Aktifitas bauran pemasaran klasik yang bergerak pada bauran yang lebih kontemporer dalam 4C nampak dari pergeseran Product menjadi Co-Creation yang diartikan sebagai hasil kreasi bersama komunitas yang bersifat dinamis. Lalu Price digantikan oleh currency yang berarti nilai tukar yang didasarkan pada perubahan produk yang dihasilkan. Kemudian transformasi Place menjadi Communal Activation yang merupakan simpul-simpul yang bisa berupa opinion leader dalam komunitas, yang menjadi pihak yang mempengaruhi konsumsi suatu produk. Dan yang terakhir adalah adanya perubahan Promotion menjadi Conversation yang merupakan suatu aktifitas memperkenalkan produk dari co-creation secara dua arah, peer to peer, many to many (lihat bagan 2.1)

\section{Bagan 2.1 Perkembangan Marketing Mix}

\begin{tabular}{lll}
\hline \multicolumn{1}{c}{ Marketing 1.0 } & \multicolumn{1}{c}{ Marketing 2.0 } & \multicolumn{1}{c}{ Marketing 3.0 } \\
\hline Product & Customer Need & Co-Creation \\
Price & Cost & Currency \\
Place & Convenience & Communal Activation \\
Promotion & Communications & Conversation \\
\hline
\end{tabular}

Sumber: Kotler, Kartajaya, Setiawan. 2010. Marketing 3.0

Perkembangan konsep Marketing 3.0 tak bisa lepas dari perkembangan teknologi internet yang lebih cepat, efisien dan jangkuan luas, membuat dunia serasa tanpa batas. Akses masyarakat yang semakin tinggi pada teknologi ini sangat menguntungkan bagi dunia pemasaran, karena di era yang berbasis informasi yang disebarkan melalui new media, para pemasar memang sangat membutuhkan medium yang bisa secara cepat pula untuk menyebarkan sebuah ide baru. Statistik yang dirilis oleh menunjukkan bahwa pengguna internet di seluruh dunia mencapai hampir dua milyar orang atau 30\% penduduk dunia terhubung melalui internet (lihat bagan 2.2). 


\section{Bagan 2.2 Statistik Penggunaan Internet \\ INTERNET USAGE STATISTICS The Internet Big Picture \\ World Internet Users and Population Stats}

\begin{tabular}{|c|c|c|c|c|c|c|}
\hline \multicolumn{7}{|c|}{ WORLD INTERNET USAGE AND POPULATION STATISTICS } \\
\hline World Regions & $\begin{array}{l}\text { Population } \\
\text { ( } 2010 \text { Est.) }\end{array}$ & $\begin{array}{l}\text { Internet Users } \\
\text { Dec. } 31,2000\end{array}$ & $\begin{array}{l}\text { Internet Users } \\
\text { Latest Data }\end{array}$ & $\begin{array}{c}\text { Penetration } \\
\text { (\% Population) }\end{array}$ & $\begin{array}{c}\text { Growth } \\
2000-2010\end{array}$ & $\begin{array}{l}\text { Users \% } \\
\text { of Table }\end{array}$ \\
\hline Africa & $1,013,779,050$ & $4,514,400$ & $110,931,700$ & $10.9 \%$ & $2,357.3 \%$ & $5.6 \%$ \\
\hline Asia & $3,834,792,852$ & $114,304,000$ & $825,094,396$ & $21.5 \%$ & $621.8 \%$ & $42.0 \%$ \\
\hline Europe & $813,319,511$ & $105,096,093$ & $475,069,448$ & $58.4 \%$ & $352.0 \%$ & $24.2 \%$ \\
\hline Middle East & $212,336,924$ & $3,284,800$ & $63,240,946$ & $29.8 \%$ & $1,825.3 \%$ & $3.2 \%$ \\
\hline North America & $344,124,450$ & $108,096,800$ & $266,224,500$ & $77.4 \%$ & $146.3 \%$ & $13.5 \%$ \\
\hline Latin America/Caribbean & $592,556,972$ & $18,068,919$ & $204,689,836$ & $34.5 \%$ & $1,032.8 \%$ & $10.4 \%$ \\
\hline Oceania / Australia & $34,700,201$ & $7,620,480$ & $21,263,990$ & $61.3 \%$ & $179.0 \%$ & $1.1 \%$ \\
\hline WORLD TOTAL & $6,845,609,960$ & $360,985,492$ & $1,966,514,816$ & $28.7 \%$ & $444.8 \%$ & $100.0 \%$ \\
\hline \multicolumn{7}{|c|}{$\begin{array}{l}\text { NOTES: (1) Internet Usage and World Population Statistics are for June } 30,2010 \text {. (2) CLICK on each world region name for } \\
\text { detailed regional usage information. (3) Demographic (Population) numbers are based on data from the US Census Bureau - (4) } \\
\text { Internet usage information comes from data published by Nielsen Online, by the International Telecommunications Union, by } \\
\text { GfK, local Regulators and other reliable sources. (5) For definitions, disclaimer, and navigation help, please refer to the Site }\end{array}$} \\
\hline
\end{tabular}

Sumber: http://digilib.itb.ac.id

Teknologi internet kemudian menjadi pemicu perubahan cara berkomunikasi. Yang dilakukan oleh Surya Dwiartha mengenai dampak penggunaan internet terhadap perubahan pola perilaku masyarakat perkotaan, memperlihatkan delapan temuan yang menarik. Pertama, terjadi evolusi penggunaan internet, dari penggunaan untuk fungsi sederhana (komunikasi) menjadi penggunaan dengan fungsi yang spesifik. Kedua, pengguna internet merupakan masyarakat yang berpendidikan tinggi (well educated) dan mampu secara finansial (well financed). Ketiga, dampak yang teridentifikasi akibat penggunaan internet secara intensif dapat dibagi berdasarkan pola pergerakan, pola aktivitas dan implikasinya terhadap interaksi sosial. Keempat, tidak ada reduksi pergerakan di masyarakat yang terjadi akibat penggunaan internet kecuali untuk beberapa perjalanan yang tidak rutin dilakukan. Kelima, pola aktivitas masyarakat mengalami perubahan dengan makin banyaknya profesi yang terkait dengan pemanfaatan internet untuk digunakan sebagai bagian dari pekerjaan. Keenam, menemukan interaksi sosial sebagai implikasi dari berubahnya pola pergerakan, dan pola aktivitas, yang ditandai dengan menurunnnya intensitas pertemuan tatap muka untuk melakukan komunikasi sederhana seperti mengobrol dan diskusi, sedangkan pertemuan yang membutuhkan kontak fisik dan ikatan emosional kuat tidak dapat digantikan oleh penggunaan internet. Ketujuh, menjelaskan dampak yang ditimbulkan setelah penggunaan internet secara intensif merupakan salah satu bentuk dari fenomena 'time space compression' yang membuat masyarakat menjadi lebih statis dan tidak membutuhkan pengalokasian lahan khusus untuk melakukan aktivitas. Kedelapan, rumah dan warnet menjadi lokasi yang multifungsi dengan berbagai aktivitas dapat dilakukan secara bersamaan.

Konsep marketing masa depan setidaknya memiliki tiga landasan yaitu Co-creation, Communitization dan Character Building. Co-creation adalah sebuah pendekatan baru untuk menjelaskan konsep inovasi. Menurut Prahalad dan Krishnan dalam bukunya The New Age of Innovation, produk tercipta dan terbentuk pengalamannya dari kolaborasi antara perusahaan, konsumen, pemasok dan mitra distribusi yang saling terhubung dalam suatu jaringan inovasi. Pengalaman atas produk atau product experience adalah akumulasi dari pengalaman-pengalaman individual konsumen yang menciptakan nilai utama sebuah produk. Setelah pengalaman tersebut didapatkan oleh konsumen individual yang selanjutnya menyesuaikan dengan pengalaman, serta menyesuaikan dengan kebutuhan dan keinginan.

\section{Metodologi Penelitian}

Dalam melakukan penelitian ini, metode yang digunakan adalah metode kualitatif, dimana data yang dihasilkan berupa data deskriptif tertulis atau lisan dari orang-orang dan perilaku yang dapat diamati. Pendekatan ini diarahkan pada latar dari invidu itu secara utuh . Individu dan organisasi tidak 
boleh diisolasikan ke dalam variable dan hipotesis, tapi memandangnya sebagai bagian dari sebuah keutuhan.

Penelitian kualitatif memiliki paradigma alamiah dimana berasumsi bahwa fenomena bercirikan interaktivitas. Walaupun usaha penjajagan dapat mengurangi interaktivitas sampai ke tingkatan minimum, sejumlah besar kemungkinan masih akan tetap ada. Pendekatan yang baik memerlukan pengertian tentang kemungkinan pengaruh terhadap interaktivitas, dan dengan demikian perlu memperhitungkannya.

Pendekatan yang diterapkan pada penelitian ini adalah pendekatan analisis konten yang mencoba memahami fenomena fidget spinner yang berkembang di masyarakat, ditinjau dari sudut pandang konsumerisme dan kultivasi media. Analisis menekankan pada bagaimana peneliti melihat keajekan isi komunikasi secara kualitatif, memaknakan isi komunikasi, membaca simbol-simbol, memaknakan isi interaksi simbolis yang terjadi dalam komunikasi.

\section{Hasil Penelitian Dan Pembahasan}

Fidget spinner merupakan mainan yang ditemukan oleh Catherine Hettinger, dengan ide penemuan untuk mengalihkan perhatian anak-anak muda dan memberi mereka sesuatu yang menenangkan untuk melepaskan energi yang terpendam. Ide mainan fidget spinner dimulai pada tahun 1980an, dengan mengedepankan mainan yang membantu mengobati kegelisahan dan gangguan perhatian defisit (autis). Hak patennya atas produk aslinya berakhir awal tahun 2017 dan itu berarti perusahaan seperti Hasbro dapat menjual versi mainan mereka sendiri tanpa Hettinger.

Perkembangan fidget spinner dimulai pada tahun 2017, yang dipicu oleh berakhirnya kontrak perusahaan Hasbro (produsen fidget spinner) dengan Hettinger. Berakhirnya paten milik Hettinger membuat potensi besar mainan ini, berbagai perusahaan mulai membuat produk fidget spinner sendiri dan melakukan tindakan marketing besar melalui iklan, dengan tag-line "relaxing your stress". Iklan fidget spinner menyebar dimedia sosial seperti facebook dan instagram, dan iklan paling besar dilakukan di youtube. Iklan - iklan tersebut tidak membawa dampak yang cukup besar pada awalnya, dimana kepopuleran fidget spinner mendadak melambung di tahun 2017. Hal ini terlihat dalam gambar 4.1 berikut ini:

\section{The rise of the fidget spinner}

Is the controversial device reaching peak popularity?

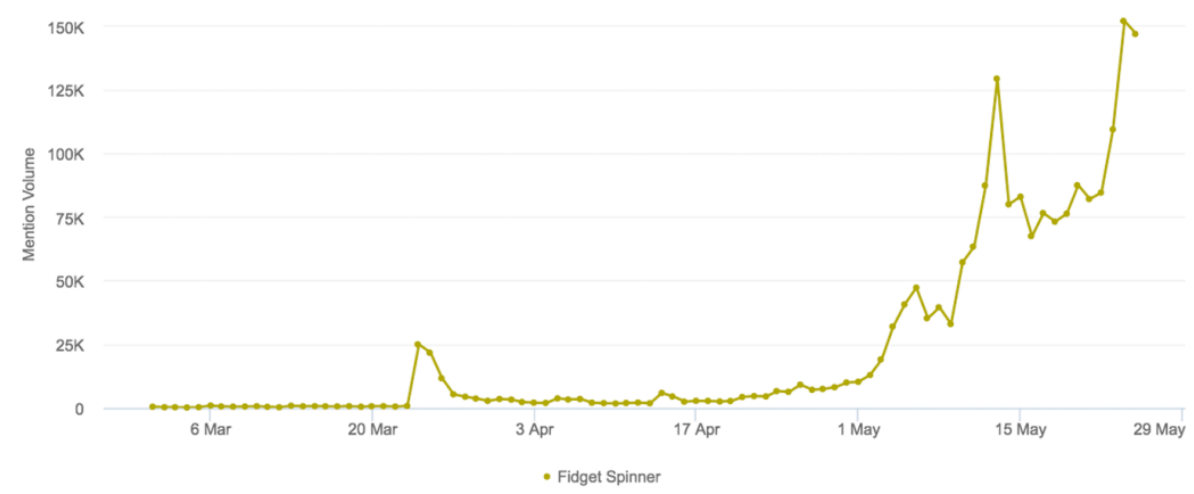

Social data analysis via @Brandwatch | 1 March - 25 May 2017

Gambar 4.1 Perkembangan Kepopuleran Fidget Spinner

Pertengahan tahun 1993 sampai dengan 2016 belum ada pembahasan ataupun pencarian terhadap fidget spinner, namun tahun 2017 dimulai pada bulan februari sampai dengan memasuki bulan mei 2017, fidget spinner popular yang terlihat pada gambar 4.1. Jika masyarakat sebelumnya adalah pembeli tanpa mencari tau fungsi dari fidget spinner, namun belakangan seiring dengan perkembangannya masyarakat mulai kritis dan mempertanyakan fungsinya. Pada akhirnya hal ini menjadi pemicu produsen fidget spinner untuk menciptakan konten fidget spinner menjadi mainan yang mengedukasi terutama meningkatkan konsentrasi (https://fastweb.media/articles). 
Konsumen yang tertarik dengan fidget spinner baik karena mendapat informasi di youtube maupun media lainnya akhirnya membeli. Hal ini sejalan dengan konsep marketing 3.0 Co-creation, Communitization dan Character Building, dimana Prahalad dan Krishnan menekankan produk tercipta dan terbentuk pengalamannya dari kolaborasi antara perusahaan, konsumen, pemasok dan mitra distribusi yang saling terhubung dalam suatu jaringan inovasi. Pengalaman atas produk fidget spinner adalah akumulasi dari pengalaman-pengalaman individual konsumen yang menciptakan nilai utama sebuah produk. Sehingga ketika konsumen melakukan review dengan mengulas permainan fidget spinner, dan meng-upload video permainan fidget spinner yang mereka mainkan ke media sosial (youtube), secara tidak langsung telah menjadi marketing bagi fidget spinner. Hal ini terlihat dalam penemuan data oleh NYTIMES (/www.nytimes.com/2017/08/15/magazine), bahwa pencarian google yang menayangkan lebih dari 2.3juta pencarian, 1,6juta review di youtube, menjadikan marketing fidget spinner berkembang menjadi marketing 3.0.

Kepopuleran fidget spinner tidak terlepas dari peran media yang berhasil mengkultivasi masyarakat (media yang dimaksud dalam hal ini adalah youtube). Youtube sebagai salah satu media banyak menayangkan iklan fidget spinner, diselingi dengan banyak review dari youtubers (reviewer youtube) sehingga menjadikan masyarakat tertarik dan secara tidak langsung mengkultivasi masyarakat untuk membeli fidget spinner (https://fastweb.media/articles). Sejalan dengan salah satu poin kultivasi menurut Garbner adalah, "Konsumsi media merupakan salah satu faktor yang membentuk persepsi pemirsa akan suatu hal dan bahkan membentuk pola perilaku tertentu terhadap hal tersebut". Kasus fidget spinner, awalnya media menampilkan iklan dengan durasi maksimal 15 detik (skip ad) di youtube, dan masyarakat yang mengkonsumsi youtube membentuk pemikirannya untuk membeli fidget spinner. Pola perilaku masyarakat yang berubah didukung dengan konten iklan yang selalu berbeda tentang fidget spinner, dimulai dari review tentang fidget spinner, iklan terkait dengan pemakaian fidget spinner, sehingga masyarakat yang sebelumnya kurang tertarik dengan iklan yang ada, menjadi ikut membelinya karena melihat keasikan youtubers saat memainkannya. Melihat fidget spinner yang semakin tenar, masyarakat kemudian ikut memamerkan aksi memainkan fidget spinner melalui youtube, bahkan sebagian ada yang mulai ikut berjualan dimedia online. Pola ini terus berputar, semakin banyak hingga akhirnya menjadikan fidget spinner pupoler.

Sistem komunikasi berperan sangat penting dalam masyarakat konsumen, terutama menyangkut produksi tanda, dan fidget spinner melalui media sosial telah memicu tingkat konsumerisme masyarakat untuk membeli fidget spinner, tanpa memandang nilai guna dari barang. Hal ini sejalan dengan pendapat Analisa Baudrillard (2004), tentang masyarakat konsumsi disarikan melalui analisa dari disiplin semiotika, psikoanalisa dan ekonomi politik dalam produksi tanda dimana orang tidak lagi mengkonsumsi objek berdasarkan karena kegunaan atau nilai tukarnya, melainkan karena nilai simbolis yang sifatnya abstrak dan terkonstruksi. Merek yang pada awalnya merupakan tolok ukur kualitas yang dapat dipercaya konsumen kini bergeser nilainya menjadi kegemaran, atau hanya sekedar "latah" terhadap suatu produk, dan hal ini berlaku bagi masyarakat yang mengkonsumsi fidget spinner.

Pada dasarnya, kemanfaatan fidget spinner dalam membantu anak - anak yang memiliki gangguan ADH ataupun mengurangi stress atau kecemasan hingga saat ini pun masih diperdebatkan oleh para ahli. Sebagian dari para ahli bahkan ada yang berpendapat bahwa sebenarnya fidget spinner ini justru akan memberikan dampak buruk. Namun sebagaimana hasil dari penelitian Jacky Murssry tentang 9 tren yang sedang berlaku di Indonesia, dua diantaranya adalah adalah, "faster product adoption leads to shorter lifecycle" dan "instan and expreriental are no longer oxymoron". Kedua tren tersebut dimiliki oleh fidget spinner, akhirnya dengan dalih "agar tidak ketinggalan zaman" dan "Aku mau coba-coba", masyarakat tanpa berfikir lebih jauh mulai mengkonsumsi fidget spinner tersebut. Dimana konsumsi pada era ini dianggap sebagai suatu respon terhadap dorongan homogenisasi dari mekanisasi dan teknologi. Orang-orang mulai menjadikan konsumsi sebagai upaya ekspresi diri yang penting, bahasa umum yang digunakan untuk mengkomunikasikan dan menginterpretasi tanda-tanda budaya.

\section{Simpulan}

Fidget spinner adalah fenomena di mana media sosial menjadi sumber yang mampu mengkultivasi masyarakat untuk melakukan tindakan sama dengan apa yang ditampilkan. Fenomena 
yang ditampilkan adalah bagaimana tingkat konsumerisme yang sebelumnya berada dalam batas berdasarkan kepada merek, seiring dengan masuknya pola komunikasi baru melalui media sosial tingkat konsumerisme menjadi "latah" dengan pola komunikasi yang meniru dengan cara melakukan reviewer yang sebelumnya dilakukan oleh reviewer lain.

Fidget spinner adalah satu dari beberapa kasus mainan yang mampu menarik masyarakat untuk mengkonsumsi tanpa melihat nilai guna, dan pola marketing 3.0 telah diterapkan dalam pola marketing fidget spinner dan masyarakat sebagai konsumen menjadi produsen dalam waktu yang bersamaan. Pola kultivasi yang terjadi adalah melalui youtube, dimana jika dalam Garbner "Konsumsi media merupakan salah satu faktor yang membentuk persepsi pemirsa akan suatu hal dan bahkan membentuk pola perilaku tertentu terhadap hal tersebut", dan konsumsi youtube adalah media yang mampu membentuk persepsi pemirsa akan suatu hal terutama dengan pola perilaku masyarakat dalam fenomena fidget spinner.

\section{Daftar Pustaka}

1) Amir Piliang, Yasraf. 2004. Dia yang dilipat: Tamasya Melampaui Batas-Batas Kebudayaan. Bandung : Jalasutra

2) Croteau, David and William Hoynes. 2014. Media/Society.Industries Images and Audiences. Fifth edition.London: Sage Publications.

3) Basrowi dan Sukidin. 200). Metode Penelitian Kualitatif Perspektif Mikro, Surabaya: Insan Cendikian.

4) Baudrillard, Jean P. diterjemahkan oleh Wahyunto. 2004. Masyarakat Konsumsi, Yogayakarta: Kreasi Wacana

5) Google Brandwatch, Fidget Spinner

6) EM Griffin. 2012, A First Look At Communication Theory. Mc Graw Hill.

7) Morissan. 2013. Teori Komunikasi: Individu Hingga Massa. Jakarta: Kencana.

8) Moleong, L.J. Metode penelitian kualitatif. 2002. Remaja Rosdakarya, Bandung.

9) Mulyana, D.N. 2001. Metode penelitian kualitatif. Remaja Rosdakarya: Bandung.

10) Mussry Jacky. 2017. Indonesia Consumer Buying Trend. Jakarta. ISMS CEO Forum

11) Sarwono, Billy K.. Saatnya Media Pro Perempuan sebuah Perspektif dalam Kajian Media. 2014.

12) Suyanto. 2002. Metode Penelitian Sosial Berbagai Alternatif Pendekatan. Kencana, Jakarta.

13) Internet:

14) https://kumparan.com/@ millennial/asal-usul-fidget-spinner-untuk-mencegah-bocah-palestinalempar-batu diakses pada tanggal 19 Desember 2017

15) https://www.msn.com/id-id/gayahidup/hidup-pintar/fidget-spinner-apakah-benar-punyamanfaat-bagi-kesehatan/ar-AApl3o1 diakses pada tanggal 19 Desember 2017 